\title{
La potencialidad del aprendizaje servicio para la personalización del aprendizaje escolar
}

Elena Martín. Universidad Autónoma de Madrid, España Mariana Solari. Universidad de Extremadura, España

Juan De Vicente. IES Miguel Catalán, España

M. Jesús Luque. IES Miguel Catalán, España

Mara Nieto. Universidad Autónoma de Madrid, España

César Coll. Universidad de Barcelona, España

\section{Resumen}

El progresivo desdibujamiento del sentido de la educación escolar está causado, entre otros factores, por el desajuste que existe entre los rasgos de la nueva ecología del aprendizaje y los supuestos sobre el aprendizaje que subyacen al diseño de los sistemas educativos. Este desfase puede ser, en parte, amortiguado mediante la personalización de los aprendizajes. El objetivo general de este trabajo es analizar la potencialidad que tiene el aprendizaje servicio para la personalización de los aprendizajes escolares. Para ello se ha diseñado una investigación que analiza en profundidad el programa de aprendizaje servicio realizado en un instituto de educación secundaria de la Comunidad de Madrid (España). Se trata de un estudio de caso, longitudinal, conformado por dos ciclos de diseño-implementación-seguimientoanálisis de resultados. Los resultados ponen de manifiesto las principales fortalezas y debilidades del programa de aprendizaje servicio estudiado.

\section{Palabras clave}

Aprendizaje servicio, educación secundaria, nueva ecología del aprendizaje, personalización. 


\title{
The potential of the service learning for the personalization of school learning
}

\begin{abstract}
The progressive blurring of the sense of school education is caused, among other factors, by the imbalance that exists between the features of the new ecology of learning and the assumptions about learning that underlie the design of educational systems. This lag can be, in part, cushioned by personalizing learning. The general objective of this work is to analyze the potential of service learning for the personalization of school learning. For this, a research has been designed that analyzes in depth the service learning program carried out in a secondary education institute of the Community of Madrid (Spain). It is a case study, longitudinal, consisting of two cycles of design-implementation-monitoring-analysis of results. The results highlight the main strengths and weaknesses of the service learning program studied.
\end{abstract}

\section{Keywords}

Service learning, secondary education, new ecology of learning, personalization. 


\section{Introducción}

Existe un amplio número de trabajos teóricos y empíricos que analizan el modo en que la metodología de aprendizaje servicio puede contribuir a la formación de ciudadanos responsables, críticos, reflexivos y comprometidos con su entorno. En concreto, esta metodología se caracteriza por combinar procesos de aprendizaje y de servicio a la comunidad en un solo proyecto bien articulado, mediante la implicación del alumnado en las necesidades reales de su entorno con la finalidad de mejorarlo (Puig, Batlle, Bosch y Palos; 2006). Entre otras contribuciones, cabe destacar el papel que desempeña el aprendizaje servicio para la educación para la ciudadanía (Puig, Gijón, Martín y Rubio, 2011), para la mejora de los resultados académicos del alumnado (Furco, 2010), para el desarrollo de su pensamiento crítico, competencias interpersonales, vocacionales y profesionales (Rubio, 2009), para el cambio de actitudes y motivación de los docentes (Furco y Billig, 2001) o para el impacto y fortalecimiento de la vinculación de la escuela con la comunidad (Tapia, 2001).

Con la finalidad de seguir profundizando en las aportaciones del aprendizaje servicio como método para unir el éxito escolar y el compromiso social (Batlle; 2011, 2013), el objetivo de este artículo es analizar la potencialidad de esta metodología para la personalización de los aprendizajes escolares. En otras palabras, presentaremos evidencias empíricas que ponen de manifiesto el modo en que las experiencias de aprendizaje servicio pueden implicar la puesta en marcha de un conjunto de estrategias organizativas, pedagógicas y didácticas que favorecen que los alumnos atribuyan un sentido personal a sus aprendizajes escolares (Coll, 2016).

Para alcanzar este objetivo, en la primera parte del artículo nos referiremos a las características de la nueva ecología del aprendizaje que se ha conformado como consecuencia de las transformaciones sociales, culturales, económicas y tecnológicas asociadas a la sociedad de la información. Posteriormente, haremos explícito qué entendemos por personalización del aprendizaje y señalaremos algunas dimensiones relevantes para su conceptualización y análisis.

En la segunda parte del texto describiremos el método utilizado para investigar el programa de aprendizaje servicio llevado a cabo en un instituto de educación secundaria (IES). Haremos referencia al diseño metodológico, los participantes de la investigación, las estrategias de recogida de información, los procedimientos de análisis de la información obtenida y las estrategias puestas en marcha para garantizar la calidad de la investigación.

En la tercera parte del artículo presentaremos algunos de los resultados obtenidos en la investigación, destacando las principales potencialidades de esta experiencia para la realización de aprendizajes escolares con un sentido y un valor personal para el alumnado

Martín, E.; Solari,M.; De Vicente, J.; Luque, M.J.; Nieto, M.; Coll, C. (2018). La potencialidad del aprendizaje servicio para la personalización del aprendizaje escolar. RIDAS, Revista Iberoamericana de Aprendizaje Servicio, 5, 37-61. DOI10.1344/RIDAS2018.5.4 
participante. Organizaremos este apartado en torno a algunas de las dimensiones de personalización de los aprendizajes que se derivan de nuestro marco teórico. Por último, cerraremos apuntando algunas conclusiones relativas tanto a la metodología de investigación como a los resultados obtenidos, y nos referiremos a algunas de las contribuciones y limitaciones de este trabajo.

\section{Marco teórico}

\subsection{La nueva ecología del aprendizaje}

Las transformaciones sociales, económicas, políticas, culturales y tecnológicas asociadas a la sociedad de la información han implicado profundos cambios en los contextos de actividad en los que las personas participamos, nos desarrollamos y aprendemos (Coll, 2013a). Ello ha llevado a que los parámetros básicos del aprendizaje humano (qué, cómo, cuándo, dónde, con quién, para qué aprender) también se hayan visto modificados, en mayor o menor medida, dando lugar a una nueva ecología del aprendizaje (Coll, 2013a, 2016). Algunos de sus rasgos básicos son que el aprendizaje se produce a lo largo de la vida (durante todos los períodos vitales y no exclusivamente durante el periodo de escolarización) y a lo ancho de la vida (en diversos contextos), y que no existe una separación nítida entre los distintos escenarios en los que se aprende, sino que los límites entre éstos son cada vez más difusos (Coll, 2016).

Como se resume en la tabla 1 , las características vertebradoras de esta nueva ecología del aprendizaje (coherente con un modelo de educación distribuida e interconectada) se contraponen en gran medida con la ecología del aprendizaje del modelo de escolarización universal, que sigue subyaciendo al diseño de la mayor parte de los sistemas educativos y las prácticas escolares.

Tabla 1. La nueva ecología del aprendizaje: hacia un modelo de educación distribuida e interconnectada

\begin{tabular}{|c|c|c|}
\hline Parámetros & $\begin{array}{l}\text { La ecología del } \\
\text { aprendizaje del } \\
\text { modelo de } \\
\text { escolarización } \\
\text { universal }\end{array}$ & $\begin{array}{c}\text { La ecología del } \\
\text { aprendizaje del } \\
\text { modelo de } \\
\text { educación } \\
\text { distribuida e } \\
\text { interconectada } \\
\end{array}$ \\
\hline $\begin{array}{l}\text { Dónde y con } \\
\text { quién se } \\
\text { aprende }\end{array}$ & $\begin{array}{l}\text { Instituciones } \\
\text { educativas } \\
\text { Profesionales de } \\
\text { la educación }\end{array}$ & $\begin{array}{l}\text { Multiplicidad de } \\
\text { escenarios } \\
\text { educativos } \\
\text { Multiplicidad de } \\
\text { agentes } \\
\text { educativos }\end{array}$ \\
\hline $\begin{array}{l}\text { Cuándo se } \\
\text { aprende }\end{array}$ & $\begin{array}{l}\text { Al inicio de la } \\
\text { vida }\end{array}$ & $\begin{array}{l}\text { A lo largo de la } \\
\text { vida }\end{array}$ \\
\hline Qué se aprende & $\begin{array}{l}\text { Saberes } \\
\text { culturales } \\
\text { "estables" } \\
\text { socialmente } \\
\text { valorados }\end{array}$ & $\begin{array}{l}\text { Competencias o } \\
\text { "habilidades } \\
\text { básicas" para el } \\
\text { siglo XXI }\end{array}$ \\
\hline $\begin{array}{l}\text { Para qué se } \\
\text { aprende }\end{array}$ & $\begin{array}{l}\text { Para poder } \\
\text { desarrollar un } \\
\text { proyecto de vida } \\
\text { personal y } \\
\text { profesional }\end{array}$ & $\begin{array}{l}\text { Para formar } \\
\text { aprendices } \\
\text { competentes } \\
\text { capaces de seguir } \\
\text { aprendiendo a lo } \\
\text { largo de la vida }\end{array}$ \\
\hline $\begin{array}{l}\text { Cómo se } \\
\text { aprende }\end{array}$ & $\begin{array}{l}\text { Mediante la } \\
\text { acción educativa } \\
\text { intencional, } \\
\text { sistemática y } \\
\text { planificada } \\
\text { (enseñanza) } \\
\text { Predominio de las } \\
\text { tecnologías } \\
\text { basadas en la } \\
\text { lengua escrita y } \\
\text { las competencias } \\
\text { exigidas para su } \\
\text { uso (leer, } \\
\text { escribir, leer y } \\
\text { escribir para } \\
\text { aprender) }\end{array}$ & $\begin{array}{l}\text { Participación en } \\
\text { comunidades de } \\
\text { interés, práctica y } \\
\text { aprendizaje } \\
\text { Utilización de } \\
\text { diferentes } \\
\text { lenguajes y } \\
\text { formatos de } \\
\text { representación de } \\
\text { la información } \\
\text { (con predominio } \\
\text { del lenguaje } \\
\text { visual) } \\
\text { Las TIC como vía } \\
\text { de acceso a la } \\
\text { información y al } \\
\text { conocimiento }\end{array}$ \\
\hline
\end{tabular}

Martín, E.; Solari,M.; De Vicente, J.; Luque, M.J.; Nieto, M.; Coll, C. (2018). La potencialidad del aprendizaje servicio para la personalización del aprendizaje escolar. RIDAS, Revista Iberoamericana de Aprendizaje Servicio, 5, 37-61. DOI10.1344/RIDAS2018.5.4 
2.2. La personalización como medio para la construcción de aprendizajes con sentido

El creciente desajuste que existe entre las respuestas que se dan a estos parámetros en la nueva ecología del aprendizaje, por un lado, y en la ecología subyacente al diseño tradicional de los sistemas educativos y de funcionamiento de los centros escolares, por el otro, ha llevado a muchos autores a reflexionar sobre el sentido que en la actualidad tienen las instituciones escolares. En esta línea, la noción de pérdida o desdibujamiento del sentido de la educación escolar (Coll, 2009, 2016), hace referencia a las dudas que se plantean, cada vez con más insistencia e intensidad, sobre si la educación escolar puede responder actualmente a las mismas finalidades y expectativas y cumplir las mismas funciones que se le han atribuido tradicionalmente (Coll, 2016: 64). Este progresivo desdibujamiento del sentido de la educación escolar es una problemática que tiene lugar en numerosos países y constituye uno de los elementos responsables del fracaso escolar, el abandono escolar y la falta de motivación de gran parte del alumnado y del profesorado (Coll, 2009, 2016; Kumpulainen y SeftonGreen, 2014).

Este fenómeno es, al menos en parte, el resultado de que los aprendizajes que tienen lugar en las escuelas e institutos se encuentran a menudo totalmente desconectados de los intereses, motivaciones y preocupaciones de los estudiantes. En este sentido, existe un hiato entre los aprendizajes escolares y las trayectorias individuales de aprendizaje de los alumnos, esto es, el conjunto de experiencias de aprendizaje que tienen en los distintos contextos de actividad en los que participan a lo largo de sus vidas (Barron, 2010; Engel y Membrive, en prensa).

Para afrontar esta situación, en algunos centros de educación primaria y secundaria de distintos países se están poniendo en marcha diversas prácticas de personalización de los aprendizajes, entendidas éstas como aquellas experiencias, propuestas y prácticas docentes cuya finalidad es que los estudiantes atribuyan un sentido personal a los aprendizajes escolares (Coll, 2013b, 2016). Personalizar los aprendizajes implica que los procesos de enseñanza y aprendizaje se ajusten no solamente a las características, necesidades y ritmos del aprendiz (idea que ya estaba presente en la noción de atención a la diversidad), sino también a sus intereses, objetivos y opciones de aprendizaje, lo cual contribuirá a la construcción de aprendizajes significativos y con sentido. Podemos afirmar, por lo tanto, que las estrategias de personalización no son un fin en sí mismo, sino que constituyen un medio a través del cual favorecer que los alumnos atribuyan un valor y un sentido personal a aquello que aprenden en los contextos de educación escolar (Coll, en prensa).

Los estudiantes atribuyen un sentido personal a sus aprendizajes cuando pueden vincular lo aprendido con sus conocimientos, experiencias y vivencias pasadas (insertándolo en sus propias historias de vida), presentes (poniéndolo en relación con sus

Martín, E.; Solari,M.; De Vicente, J.; Luque, M.J.; Nieto, M.; Coll, C. (2018). La potencialidad del aprendizaje servicio para la personalización del aprendizaje escolar. RIDAS, Revista Iberoamericana de Aprendizaje Servicio, 5, 37-61. DOI10.1344/RIDAS2018.5.4 
actividades cotidianas, sus preocupaciones y sus intereses) o futuras (asociándolo a las expectativas de su proyecto de vida personal, social y profesional) (Coll, 2016). Por lo tanto, los aprendizajes con sentido y valor personal para el aprendiz son aquellos que contribuyen, en mayor o menor grado, a la progresiva (re)construcción de su identidad.

Gráfica 1. La personalización del aprendizaje como una respuesta al desdibujamiento del sentido de la educación escolar

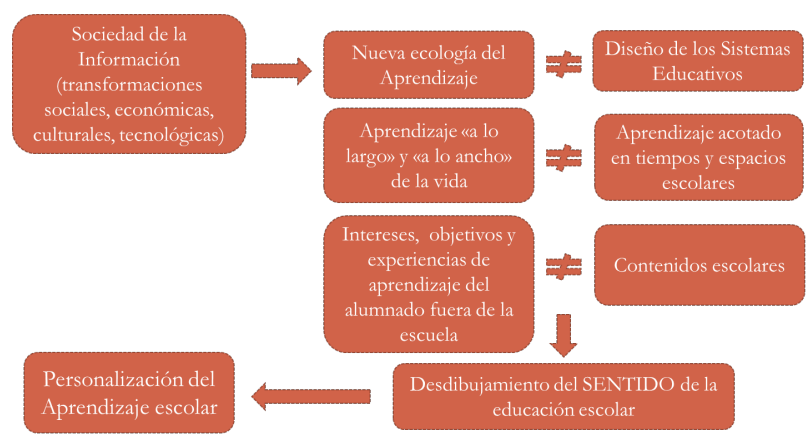

2.3. Algunas estrategias dirigidas a la personalización del aprendizaje escolar

Para avanzar hacia la personalización del aprendizaje escolar resulta conveniente poner en marcha actuaciones en diferentes niveles de concreción, que tengan un impacto sistémico en el funcionamiento del centro escolar, y que cuenten con la implicación de diversos actores. Entre estos agentes, podemos destacar el papel central del profesorado, los miembros de los equipos directivos, las familias, distintos agentes comunitarios, los administradores de la educación, o los diseñadores de políticas educativas. Si bien asumimos que para la construcción de aprendizajes con sentido es necesario introducir transformaciones en todos estos niveles, nos referiremos a continuación a un conjunto de actuaciones, formas de organización del centro, y estrategias pedagógicas y didácticas orientadas a la personalización del aprendizaje escolar y que se pueden llevar a cabo de manera más acotada, incluso en contextos socio-históricos poco favorecedores para la innovación educativa y la realización de aprendizajes con sentido.

Como desarrolla Coll (en prensa), existen algunas estrategias orientadas a la personalización que posibilitan en mayor medida que los aprendices atribuyan un sentido personal a sus aprendizajes escolares, entre las que podemos destacar las siguientes:

- Incorporación de la voz del alumnado a la toma de decisiones curriculares (identificación de intereses de aprendizaje; análisis y revisión crítica de estos intereses; preferencias sobre actividades de aprendizaje y su organización; etc.)

- Toma de decisiones compartida, o realizada directamente por el alumnado con orientación y supervisión del profesorado, sobre algunos o todos los componentes de sus procesos de enseñanza y aprendizaje (contenidos, actividades, secuenciación, materiales, apoyos, evaluación...);

- Reflexión sobre experiencias de aprendizaje, escolares y no escolares, significativas para el alumnado

- Reflexión sobre la visión que los

Martín, E.; Solari,M.; De Vicente, J.; Luque, M.J.; Nieto, M.; Coll, C. (2018). La potencialidad del aprendizaje servicio para la personalización del aprendizaje escolar. RIDAS, Revista Iberoamericana de Aprendizaje Servicio, 5, 37-61. DOI10.1344/RIDAS2018.5.4 
alumnos tienen de sí mismos como aprendices y su manera de abordar y llevar a cabo las actividades de aprendizaje, tanto en la escuela como fuera de ella

- Organización de la acción educativa a partir del establecimiento de planes personales de aprendizaje

- Énfasis en contenidos de aprendizaje social y culturalmente relevantes mediante la participación en actividades e iniciativas comunitarias

- Énfasis en el desarrollo y adquisición de competencias y en el uso de procedimientos e instrumentos de evaluación competencial

- Incorporación y aprovechamiento de recursos y oportunidades de aprendizaje presentes en la comunidad, o disponibles y accesibles en Internet

- Utilización de metodologías de indagación (aprendizaje basado en proyectos, casos y problemas; talleres creativos) para el abordaje de actividades auténticas, complejas y relevantes para el alumnado

- Utilización de las TIC y de los dispositivos móviles para configurar, profundizar y en su caso revisar itinerarios individuales de aprendizaje

2.4. La potencialidad del aprendizaje servicio para la construcción de aprendizajes con sentido

A pesar de las diversas formas de denominarlo (aprendizaje-servicio, aprendizaje y servicio; aprendizaje y servicio solidario; ...) y de los distintos énfasis que se pongan, existe un gran acuerdo en definir el aprendizaje servicio como una metodología que combina el aprendizaje curricular con el servicio a la comunidad. En palabras de Batlle (2011: 51) constituye un método que permite unir éxito escolar y compromiso social: aprender a ser competentes siendo útiles a los demás. Puig, Rovira, Gijón, Martín y Rubio (2011: 53) destacan que el aprendizaje servicio conlleva:

Actividades complejas, que requieren la sistematización de objetivos y tareas, tanto de servicio como de aprendizaje; que se engranan en un proyecto bien articulado que se ejecuta en diferentes fases: diagnóstico de la realidad, desarrollo de un plan de acción, ejecución de la propuesta y obtención de resultados evaluables; y que fomentan una mirada crítica y reflexiva respecto a los retos socioculturales $y$ medioambientales de la comunidad, con la finalidad de mejorarla a través de la participación y el compromiso cívico.

Definido de este modo, y basándonos en lo explicado en los anteriores apartados, consideramos que la metodología de aprendizaje servicio cuenta con algunas características que resultan no solamente muy coherentes con el planteamiento que llevamos desarrollando, sino que también la dotan de una especial capacidad para favorecer que los estudiantes atribuyan un sentido y un valor personal a sus aprendizajes escolares.

Entre las potencialidades del

Martín, E.; Solari,M.; De Vicente, J.; Luque, M.J.; Nieto, M.; Coll, C. (2018). La potencialidad del aprendizaje servicio para la personalización del aprendizaje escolar. RIDAS, Revista Iberoamericana de Aprendizaje Servicio, 5, 37-61. DOI10.1344/RIDAS2018.5.4 
aprendizaje servicio podemos destacar, en primer lugar, que éste asume el papel protagónico de los alumnos, dotándoles de voz y reconociendo su capacidad para tomar decisiones sobre el modo en que ofrecen un determinado servicio a la comunidad. Asimismo, se propone atender solidariamente a una necesidad real y sentida por la comunidad, lo que se corresponde con lo que Tapia (2001) denomina intencionalidad solidaria. Por otra parte, esta metodología propicia la vinculación de los aprendizajes que tienen lugar en la escuela con aquellos que suceden en otros contextos de actividad no escolares, al tiempo que organiza los aprendizajes en torno a las propias experiencias (Martín, 2009, 2016), y favorece el desarrollo de la competencia de aprender a aprender (Martín y Moreno, 2007) a partir de la reflexión del alumnado sobre sus propios procesos de aprendizaje. Otra potencialidad que desde la perspectiva de la personalización tiene el aprendizaje servicio es que plantea situaciones contextualizadas, auténticas y que deben ser abordadas interdisciplinarmente (Puig, Gijón, Martín y Rubio, 2011). Por último, esta metodología contribuye al desarrollo competencial del alumnado mediante la adquisición de competencias interpersonales, vocacionales, profesionales, para el pensamiento crítico, para la realización de proyectos, o para la ciudadanía y transformación social, entre otras (Rubio, 2009).

En resumen, desde el marco teórico de la personalización, consideramos que estas características vertebradoras de las experiencias de aprendizaje servicio tienen (al menos, potencialmente) una gran capacidad para desencadenar procesos educativos proclives a generar aprendizajes con valor y sentido personal para el alumnado que participa en ellas. Es justamente esta reflexión la que nos ha llevado a diseñar una investigación, mediante la cual poder obtener evidencias empíricas cuyo análisis nos ayude a seguir profundizando en esta línea, a través de la identificación de las potencialidades y obstáculos que el aprendizaje servicio tiene para la personalización de los aprendizajes escolares.

\section{Metodología}

\subsection{Objetivos de la investigación}

El objetivo general de la investigación es describir y comprender el modo en que los proyectos de aprendizaje servicio desarrollados en un instituto de educación secundaria favorecen la construcción de aprendizajes con sentido.

Para alcanzar este objetivo general, se plantearon los siguientes objetivos específicos:

1. Identificar los aprendizajes que los docentes persiguen con el programa y contrastarlos con los que se abordan durante el proceso y los que se evalúan durante y al final del mismo

2. Identificar los procedimientos que se ponen en marcha para conocer y responder a los intereses de los estudiantes y los procedimientos de participación de estos en las distintas fases de los proyectos

Martín, E.; Solari,M.; De Vicente, J.; Luque, M.J.; Nieto, M.; Coll, C. (2018). La potencialidad del aprendizaje servicio para la personalización del aprendizaje escolar. RIDAS, Revista Iberoamericana de Aprendizaje Servicio, 5, 37-61. DOI10.1344/RIDAS2018.5.4 
3. Analizar la influencia de los proyectos sobre la construcción de la identidad de aprendiz y personal del alumnado

4. Conocer los aprendizajes que los estudiantes dicen haber adquirido y los que sus docentes identifican

5. Contrastar la valoración que el alumnado hace de los proyectos con la valoración de sus docentes

6. Identificar los facilitadores y obstáculos para la personalización de los aprendizajes escolares

\subsection{Diseño metodológico de la} investigación

Para alcanzar los objetivos de la investigación, se ha realizado un estudio de caso, de tipo instrumental, cualitativo y longitudinal (Caïs, Folguera y Formoso, 2014; Stake, 1998), en el que se analizó el programa de aprendizaje servicio llevado a cabo en el instituto de educación secundaria (IES) Miguel Catalán (Madrid, España) ${ }^{1}$.

Con la voluntad de superar las habituales barreras existentes entre investigación y práctica educativa y entre investigadores y docentes, se ha realizado una variante del enfoque de investigación basada en el diseño y la implementación de propuestas

educativas -Design-based implementation research, DBIR(Fishman, Penuel, Allen, Cheng y Sabelli, 2013). Este enfoque reposa sobre los siguientes principios básicos:

1 Esta experiencia corresponde a uno de los centros estudiados dentro de una investigación de mayor envergadura (estudio de casos múltiples) para la que se seleccionaron distintos colegios e institutos de Madrid, Barcelona, Lleida y México D.F.
- Pone el foco en problemas prácticos persistentes y aspectos relevantes de la práctica desde el punto de vista de los distintos actores implicados

- Utiliza una lógica iterativa basada en el encadenamiento de ciclos de diseño de la actuación / implementación del diseño realizado / análisis y valoración de los resultados obtenidos / rediseño de la actuación / implementación de la actuación rediseñada / ...

- Adopta el principio de colaboración entre investigadores, profesores y otros actores implicados durante todo el proceso de investigación

- Tiene como finalidad generar al mismo tiempo teoría y conocimiento sobre los procesos de aprendizaje escolar y sobre la implementación de innovaciones educativas, mediante procesos de investigación sistemática

- Trata de desarrollar en los actores implicados la capacidad para generar cambios sostenibles en una perspectiva sistémica.

En concreto, nuestra investigación tiene una duración de dos años y cuenta con dos ciclos completos de diseñoimplementación-seguimiento-análisis. El primer ciclo (curso 2016-2017) se focaliza en el análisis de las experiencias de aprendizaje servicio que ya se estaban realizando en el centro, mientras que el segundo ciclo (curso 2017-2018) se centra en analizar la implementación de las propuestas de mejora que se

Martín, E.; Solari,M.; De Vicente, J.; Luque, M.J.; Nieto, M.; Coll, C. (2018). La potencialidad del aprendizaje servicio para la personalización del aprendizaje escolar. RIDAS, Revista Iberoamericana de Aprendizaje Servicio, 5, 37-61. DOI10.1344/RIDAS2018.5.4 
introdujeron en la experiencia, a partir del análisis conjunto de los resultados obtenidos en el primer ciclo. Los resultados que presentamos en este artículo se corresponden con la información obtenida en el primer ciclo de la investigación, que tuvo lugar entre enero y septiembre de 2017.

\subsection{Participantes}

EI IES Miguel Catalán es un centro público que imparte educación secundaria tanto en su etapa obligatoria (ESO, 12-16 años) como en la posobligatoria en las modalidades de Bachillerato y de Formación Profesional (16-19 años). Se encuentra ubicado en un barrio del Municipio de Coslada de la Comunidad de Madrid, cuenta con 56 profesores y su población (556 estudiantes) pertenece a una clase sociocultural media-baja.

El instituto cuenta desde hace 8 años con un programa de aprendizaje servicio tanto en la ESO como en Bachillerato en el que participa todo el alumnado del centro, y que está conformado por 23 proyectos distribuidos en los distintos cursos ${ }^{2}$. Mediante el programa de aprendizaje servicio, el centro persigue los siguientes objetivos: 1) promover la mejora de la convivencia en el centro, 2) desarrollar las competencias sociales y de ciudadanía del alumnado, 3)

${ }^{2}$ En la página web del instituto

(http://miguelcatalan.org/wp/) se pueden consultar los diferentes proyectos en marcha, tanto de aprendizaje servicio, como de otras líneas de trabajo. En el apartado Nuestros proyectos puede leerse una descripción detallada de algunos de los proyectos más relevantes de los últimos cursos. desarrollar la conciencia moral del alumnado, y 4) vincular los currículos de las diferentes materias que se imparten en el centro con las necesidades sociales del entorno.

Los resultados que presentaremos en este artículo se corresponden con un doble nivel de análisis. Por una parte, en un nivel macro, se presenta la valoración que el conjunto de los docentes implicados en los proyectos de aprendizaje servicio $(n=13)$ y los estudiantes de $4^{\circ}$ de la ESO y $1^{\circ}$ de Bachillerato $(n=116)$ realizan de su experiencia. Estos alumnos y alumnas han venido participando en proyectos de ApS desde el primer curso de la Educación Secundaria Obligatoria. Por otra parte, en un nivel micro, se ha realizado un seguimiento en profundidad de uno de los proyectos, relacionado con la Memoria Histórica, analizando las distintas actividades que en él se llevaron a cabo.

El objetivo de este proyecto de Memoria Histórica era promover las relaciones intergeneracionales entre los estudiantes y las personas mayores del municipio, a través del estudio de sus vivencias durante la posguerra española, centrándose cada curso académico en un aspecto determinado de la vida cotidiana. En el curso 20162017 se focalizaron en los juegos de la época.

En una primera fase, los alumnos prepararon en las clases de Lengua e Historia el guión de las entrevistas que posteriormente realizaron a personas mayores del municipio. Los alumnos transcribieron y analizaron las respuestas de la persona mayor a la

Martín, E.; Solari,M.; De Vicente, J.; Luque, M.J.; Nieto, M.; Coll, C. (2018). La potencialidad del aprendizaje servicio para la personalización del aprendizaje escolar. RIDAS, Revista Iberoamericana de Aprendizaje Servicio, 5, 37-61. DOI10.1344/RIDAS2018.5.4 
que habían entrevistado y, a través de un editor de textos, prepararon una ficha siguiendo una plantilla en la que se recoge la semblanza de la persona mayor y las características del juego que ha relatado. Como complemento para comprender esta etapa histórica, los estudiantes y algunos de los mayores se desplazaron a una localidad de las afueras de Madrid, en la que se conservan importantes restos de búnkeres y trincheras del Frente de Madrid.

En la segunda fase del proyecto se realizaron las actividades de preparación de la exposición de juguetes de la época. Ello supuso localizarlos y catalogarlos, documentarse, a través del documental Las cajas negras que explica cómo se protegieron las obras de arte durante la guerra civil, y preparar el cartel de la exposición Generaciones en juego.

En la tercera fase se llevaron a cabo dos exposiciones, una en el Centro Cultural Margarita Nelken de Coslada y otra en el Museo Lázaro Galdiano de Madrid, donde los estudiantes de $4^{\circ}$ de la ESO prepararon juegos en los jardines del museo para el alumnado de $1^{\circ}$ de la ESO de su Instituto, así como para otros visitantes e hicieron de guías en la exposición, durante los cuatro días de duración de la misma. A modo de cierre, se elaboró una pequeña publicación con las semblanzas de algunos de los mayores y la explicación de ciertos juegos, a partir de la compilación de los textos que los estudiantes habían realizado en la primera fase del proyecto.
Las características de este proyecto concreto (tratamiento de los contenidos disciplinares en las materias; diseño de instrumentos para conocer $\mathrm{y} / \mathrm{o}$ intervenir en la realidad de su entorno; elaboración de un producto final que permite difundir el proyecto) son comunes al resto de los que configuran el programa de aprendizaje servicio del Instituto.

\subsection{Estrategias de recogida de información}

Para los dos niveles de análisis a los que se ha hecho referencia (valoración del programa de aprendizaje servicio en su conjunto y análisis del proyecto de Memoria Histórica, en profundidad), se utilizaron estrategias de recogida de información complementarias, que hemos resumido en la tabla 2 .

Tabla 2. Estrategias de recogida de información utilitzada

\begin{tabular}{|c|c|c|}
\hline \multicolumn{2}{|l|}{ Entrevistas } & $\begin{array}{c}\text { Con el equipo } \\
\text { coordinador del } \\
\text { Programa (6) } \\
\text { Con conservadora del } \\
\text { Museo Arqueológico } \\
\text { de Madrid (1) } \\
\text { Con docentes (6) } \\
\text { Con estudiantes (7) }\end{array}$ \\
\hline \multicolumn{2}{|c|}{ Grupo de discusión } & 3 \\
\hline \multicolumn{2}{|c|}{ Análisis documental } & $\begin{array}{c}\text { Documentos } \\
\text { institucionales, } \\
\text { Correos electrónicos, } \\
\text { Materiales docentes, } \\
\text { Materiales de las } \\
\text { exposiciones }\end{array}$ \\
\hline \multirow{2}{*}{ Observaciones } & Clases & 2 \\
\hline & $\begin{array}{l}\text { Entrevistas } \\
\text { en Centros }\end{array}$ & 3 \\
\hline
\end{tabular}

Martín, E.; Solari,M.; De Vicente, J.; Luque, M.J.; Nieto, M.; Coll, C. (2018). La potencialidad del aprendizaje servicio para la personalización del aprendizaje escolar. RIDAS, Revista Iberoamericana de Aprendizaje Servicio, 5, 37-61. DOI10.1344/RIDAS2018.5.4 


\begin{tabular}{|l|l|c|}
\hline & de mayores & \\
\cline { 2 - 3 } & Exposiciones & 5 \\
\hline \multirow{4}{*}{ Cuestionarios } & Profesorado & 13 \\
\cline { 2 - 3 } & Alumnado & 65 \\
\cline { 2 - 3 } & $\begin{array}{l}\text { Alumnado } \\
\text { Memoria } \\
\text { Histórica }\end{array}$ & 51 \\
\hline
\end{tabular}

\subsection{Análisis de información}

Para poder analizar en qué medida la experiencia de aprendizaje servicio estudiada favorece la personalización de los aprendizajes escolares, hemos utilizado las siguientes dimensiones de análisis, que se corresponden con algunas de las estrategias de personalización apuntadas en el marco teórico:

- Atención a los intereses y objetivos de aprendizaje del alumnado

- Reconocimiento y aceptación de la capacidad del alumnado para tomar decisiones sobre alguno o algunos de los aspectos implicados en los procesos de aprendizaje

- Toma en consideración de las experiencias de aprendizaje del alumnado fuera de la escuela y su incorporación a las actividades escolares de enseñanza y aprendizaje

- Énfasis en el desarrollo y adquisición de competencias y en el uso de procedimientos e instrumentos de evaluación competencial

- Utilización de recursos y oportunidades de aprendizaje comunitarios externos a los centros
- Utilización de recursos y oportunidades de aprendizaje disponibles y accesibles a través de Internet

- Uso de las tecnologías digitales y dispositivos móviles como instrumentos de personalización del aprendizaje escolar

- Énfasis en aprendizajes social y culturalmente relevantes

- Uso de metodologías de indagación

- Reflexión sobre las experiencias de aprendizaje del alumnado con independencia del contexto en que han tenido lugar

- Reflexión sobre la visión que los alumnos tienen de sí mismos como aprendices y sobre su manera de abordar las situaciones y actividades de aprendizaje

Algunas de las estrategias utilizadas para garantizar la calidad de la recogida y análisis de la información son el compromiso prolongado en el campo, la reflexividad, la triangulación de métodos (entrevistas, observaciones, encuesta y análisis documental), la triangulación entre investigadores (tres expertas en la materia) y la triangulación con los participantes (Creswell, 2013; del Olmo, 2008; Stake, 1998).

Esta última estrategia resultó especialmente relevante por haber dado a los miembros del equipo coordinador la oportunidad de leer y dar su opinión no sólo sobre las

Martín, E.; Solari,M.; De Vicente, J.; Luque, M.J.; Nieto, M.; Coll, C. (2018). La potencialidad del aprendizaje servicio para la personalización del aprendizaje escolar. RIDAS, Revista Iberoamericana de Aprendizaje Servicio, 5, 37-61. DOI10.1344/RIDAS2018.5.4 
transcripciones realizadas, sino también sobre las interpretaciones e inferencias realizadas a partir de ellas. Sus comentarios contribuyeron a la legitimación de la mayor parte de los análisis y permitieron matizar algunas de las interpretaciones realizadas inicialmente.

\section{Resultados}

Organizaremos los resultados de la investigación en seis apartados. En el primero de ellos presentaremos los resultados vinculados con el modo en que el proyecto contribuyó a mejorar la convivencia escolar, debido a que este era uno de los principales objetivos con los que se implementó esta metodología en el IES Miguel Catalán. En los siguientes bloques analizaremos el programa de aprendizaje servicio a partir de algunas de las dimensiones de personalización de los aprendizajes escolares. En concreto, nos referiremos al desarrollo competencial del alumnado; la repercusión de los aprendizajes escolares sobre sus experiencias de aprendizaje en otros contextos; la vinculación de los aprendizajes con las necesidades sociales del entorno comunitario; la atención a los intereses y objetivos de aprendizaje del alumnado y aceptación de su capacidad para tomar decisiones sobre algunos aspectos de su proceso de aprendizaje; y la reflexión sobre sí mismos como aprendices.

\subsection{Repercusión del aprendizje servicio} en la mejora de la convivencia en el centro

Como explicamos anteriormente, uno de los principales motivos que llevó al
IES Miguel Catalán a poner en marcha los proyectos de aprendizaje servicio fue la mejora de la convivencia en el centro. Asimismo, el buen clima entre los distintos miembros de la comunidad educativa supone una condición favorecedora para que los alumnos puedan realizar aprendizajes significativos y a los que atribuyan un sentido personal.

A partir de los resultados obtenidos, podemos concluir que la experiencia de aprendizaje servicio ha contribuido a establecer un nivel muy alto de identificación del alumnado con el centro escolar $y$, con ello, ha mejorado el clima de convivencia. Como se puede observar en las siguientes gráficas, tanto el alumnado como el profesorado del centro consideran que los proyectos de aprendizaje servicio han resultado útiles para mejorar la relación entre compañeros de clase y entre los estudiantes y los docentes, al tiempo que contribuyó a aumentar la motivación del alumnado y las ganas de asistir al Instituto.

Martín, E.; Solari,M.; De Vicente, J.; Luque, M.J.; Nieto, M.; Coll, C. (2018). La potencialidad del aprendizaje servicio para la personalización del aprendizaje escolar. RIDAS, Revista Iberoamericana de Aprendizaje Servicio, 5, 37-61. DOI10.1344/RIDAS2018.5.4 
Gráfica 2. Perspectiva del profesorado $(n=13)$ y el alumnado $(n=65)$ acerca del grado de utilidad del aprendizaje servicio ( $1=$ mínima utilidad; $6=$ máxima utilidad).

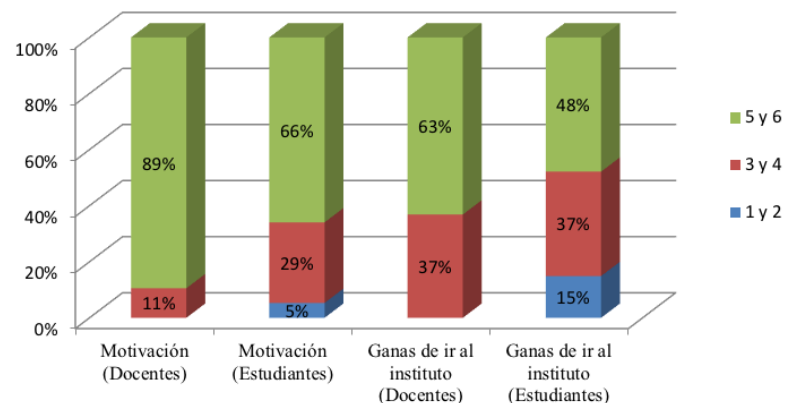

Gráfica 3. Perspectiva del profesorado $(n=13)$ y alumnado $(n=65)$ acerca del grado de utilidad del aprendizaje servicio ( $1=$ mínima utilidad; $6=$ máxima utilidad).

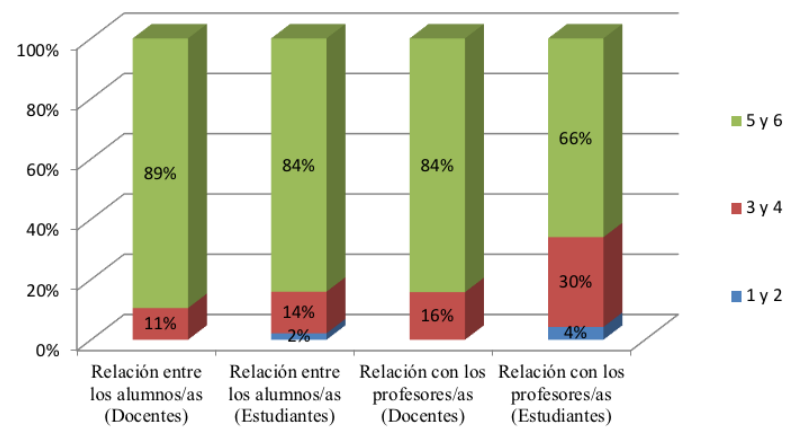

Complementariamente, la mayoría de los docentes consideran que su participación en proyectos de aprendizaje servicio ayuda a mejorar su relación con el resto del profesorado con el que los comparte el proyecto, como se pone de manifiesto en la siguiente declaración de uno de los docentes:

Si eliminamos las barreras entre yo soy de Lengua, tú de Historia, él de Biología, la relación con los alumnos se hace diferente, la relación con los compañeros de trabajo se hace diferente.

Descubres a las personas. Ya no es solamente un compañero de trabajo, es un compañero de proyecto. Digamos que hay una parte muy enriquecedora a nivel humano.

\subsection{El desarrollo competencial del} alumnado

La información recogida a través de los cuestionarios pone de manifiesto que, tanto para los docentes como para los estudiantes, los proyectos de aprendizaje servicio han implicado una innovación metodológica valiosa que ha contribuido a mejorar los procesos de aprendizaje y al desarrollo de competencias en el alumnado. En las gráficas 4 y 5 se puede observar la valoración que hacen ambos colectivos acerca de algunas características metodológicas del proyecto de aprendizaje servicio.

Gráfica 4. Valoración de los docentes $(n=13)$ de las características metodológicas del Aprendizaje-Servicio (1= mínimo grado de acuerdo; 6= máximo grado de acuerdo)

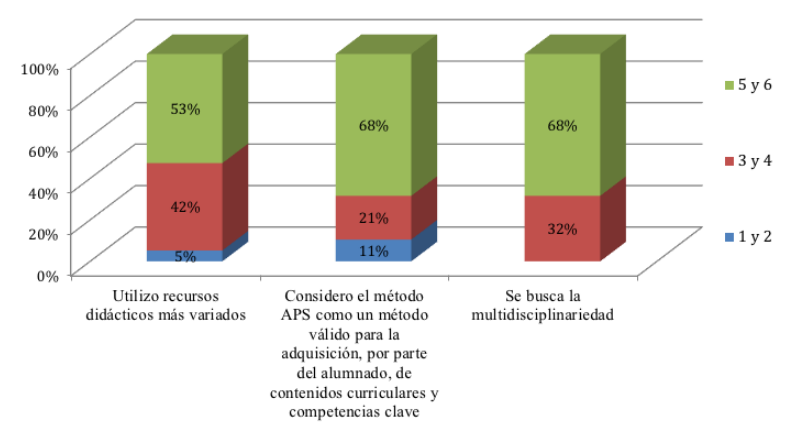

Martín, E.; Solari,M.; De Vicente, J.; Luque, M.J.; Nieto, M.; Coll, C. (2018). La potencialidad del aprendizaje servicio para la personalización del aprendizaje escolar. RIDAS, Revista Iberoamericana de Aprendizaje Servicio, 5, 37-61. DOI10.1344/RIDAS2018.5.4 
Gráfica 5. Valoración de los estudiantes $(n=65)$ de las características metodológicas del Aprendizaje-Servicio (1= mínimo grado de acuerdo; $6=$ máximo grado de acuerdo

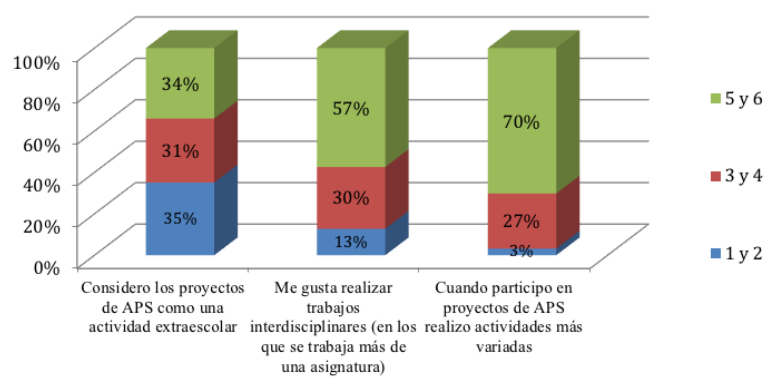

Asimismo, los estudiantes aluden a estos cambios en las entrevistas para explicar por qué aprenden mejor a través de estas experiencias, como ponen de manifiesto los estudiantes de $4^{\circ}$ de ESO en los siguientes fragmentos:

Aquí [en ApS] te lo cuentan y lo entiendes, en clase te lo cuentan para que lo estudies. A mí, con lo que me ha explicado Ángeles [persona mayor a la que entrevistó] ya no se me va a olvidar nunca la cartilla de racionamiento. Lo leía, pero no lo entendía y en cambio ahora lo comprendo.

Aquí es una vivencia, totalmente diferente a los libros.

La explicación de uno de los docentes del proyecto Memoria Histórica resume en pocas palabras la potencialidad de esta metodología para desarrollar competencias transversales:

Lo que me llevó a incorporarme al aprendizaje servicio es que me interesa todo lo que sea interdepartamental, transversal, lo que sea salir de los supuestos currículos de materias en compartimentos estancos... El ApS es la abolición de un sistema de curriculum estanco $y$ al llevarlo a cabo te das cuenta de que aprendes tú, aprenden ellos, se crea una sensación de pertenencia al grupo. Yo por ejemplo no he puesto un parte nunca, lo he podido gestionar de otra manera. Si alguno se pasa demasiado, se le dice porque, como hay un desarrollo con este tipo de proyectos de la amistad, se lo puede decir un compañero.

Por otra parte, se constata en muchas de las respuestas de los estudiantes una tendencia a considerar que los aprendizajes que se realizan en los proyectos de aprendizaje servicio no son propiamente curriculares. Esto no quiere decir que no los consideren importantes, pero sí puede interpretarse como una dificultad en aceptar que las competencias no son solo las disciplinares y que, de hecho, todo lo que se aprende en estas experiencias forma parte del curriculum. Las siguientes afirmaciones de estudiantes de $4^{\circ}$ ESO y $2^{\circ}$

Bachillerato ilustran esta idea:

$$
\begin{aligned}
& \text { Aprendemos cosas que no es } \\
& \text { temario, pero que también son } \\
& \text { importantes. }
\end{aligned}
$$

\section{Contribuye no tanto a nivel académico, pero como formación como persona.}

Para concluir con la potencialidad del aprendizaje servicio para el desarrollo de competencias en el alumnado, a

Martín, E.; Solari,M.; De Vicente, J.; Luque, M.J.; Nieto, M.; Coll, C. (2018). La potencialidad del aprendizaje servicio para la personalización del aprendizaje escolar. RIDAS, Revista Iberoamericana de Aprendizaje Servicio, 5, 37-61. DOI10.1344/RIDAS2018.5.4 


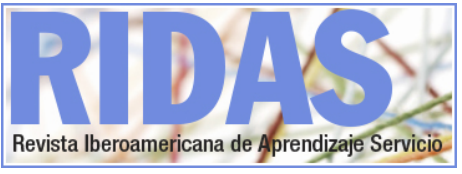

continuación podemos ver las respuestas que estudiantes y docentes ofrecieron cuando se les pidió en el cuestionario que indicaran en qué grado el proyecto en el que habían participado había contribuido al aprendizaje del temario de la asignatura, al desarrollo de sus capacidades o a la competencia para trabajar en grupo. En términos generales, comprobamos que ambos colectivos perciben que el proyecto de aprendizaje servicio ha contribuido en mayor medida al desarrollo de competencias en el alumnado que a la adquisición de contenidos conceptuales disciplinares.

Gráfica 6: Valoración de docentes $(n=13)$ y estudiantes $(n=65)$ de la contribución del Aprendizaje-Servicio a distintos aprendizajes ( $1=$ mínimo grado de acuerdo; $6=$ máximo grado de acuerdo

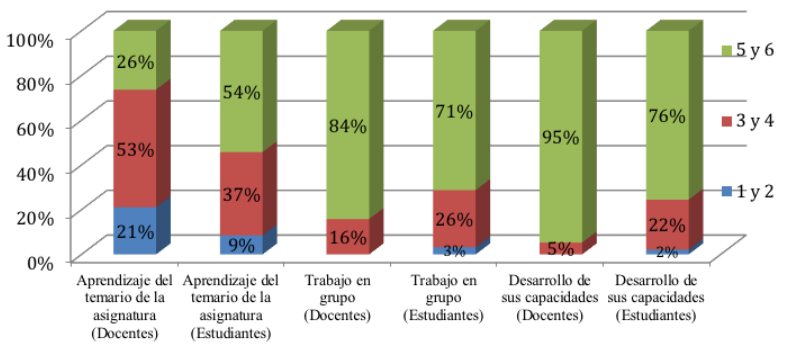

Fuertemente vinculado con el desarrollo competencial, el tema de la evaluación y la calificación de los aprendizajes merece especial atención. Se considera fundamental, tanto por profesores como por estudiantes, la inclusión de esta experiencia en la nota de las materias implicadas. Además, como se observa en la gráfica 7 , los estudiantes consideran mayoritariamente que la calificación obtenida es justa y sienten reconocido el trabajo que realizaron en el marco del proyecto de aprendizaje servicio.

Gráfica 7: Valoración de los estudiantes de los procedimientos de evaluación y calificación

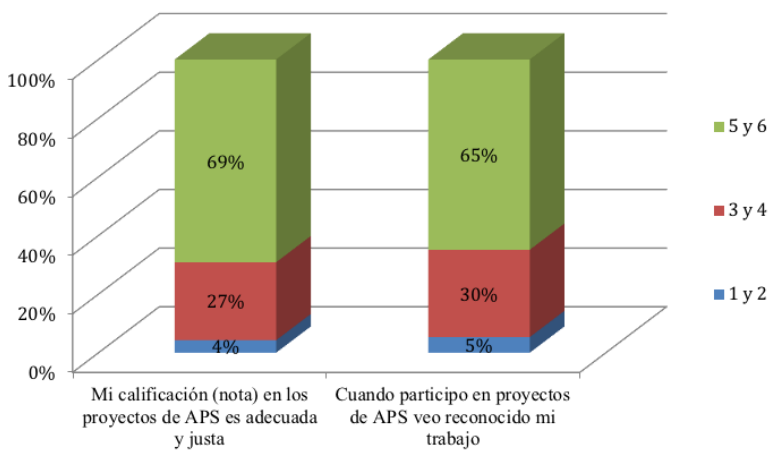

No obstante, los docentes del proyecto de Memoria Histórica señalan que les resulta difícil evaluar gran parte de los aprendizajes (competenciales) que, de hecho, se producen en los proyectos:

Es difícil comprobar si han aprendido o no porque el examen es básicamente conceptual. Uno ve que han aprendido otras cosas, pero no se pueden evaluar... A lo mejor a nosotros nos falta profundizar en ver lo que han conseguido, pero cuando has trabajado en clase cómo hacemos una entrevista y luego van y la hacen, pues vemos que la han aprendido.

No tengo la certeza de que haya una herramienta que lo mida de verdad. Me da miedo un documento que lo deje encajonado. Yo sé por ejemplo que la manera en la que nos tratamos es ahora diferente.

Martín, E.; Solari,M.; De Vicente, J.; Luque, M.J.; Nieto, M.; Coll, C. (2018). La potencialidad del aprendizaje servicio para la personalización del aprendizaje escolar. RIDAS, Revista Iberoamericana de Aprendizaje Servicio, 5, 37-61. DOI10.1344/RIDAS2018.5.4 
4.3. Repercusión de los aprendizajes en aprendizaje servicio sobre sus experiencias de aprendizaje en otros contextos

Desde el marco teórico de la personalización, para que los alumnos atribuyan un sentido y un valor personal a sus aprendizajes resulta conveniente que aquello que aprenden en el contexto escolar pueda vincularse y repercutir sobre las actividades que realizan en otros contextos, ya sea en el presente o en el futuro.

La siguiente gráfica pone de manifiesto el grado en que el profesorado y alumnado consideran que lo que aprenden en los proyectos de aprendizaje servicio tiene utilidad y repercusión sobre otros aspectos de su vida, tanto en contextos escolares (otras asignaturas) y no escolares (su vida personal) del presente como de su futuro (orientación profesional). Si bien ambos colectivos reconocen de manera similar esta contribución del aprendizaje servicio, vemos que los docentes identifican en mayor medida la utilidad que lo que están aprendiendo tiene para la vida personal de los estudiantes.
Gráfica 8: Valoración de docentes $(n=13)$ y estudiantes $(n=65)$ de la utilidad del Aprendizaje-Servicio para distintos aspectos de su vida (1= mínimo grado de acuerdo; $6=$ máximo grado de acuerdo

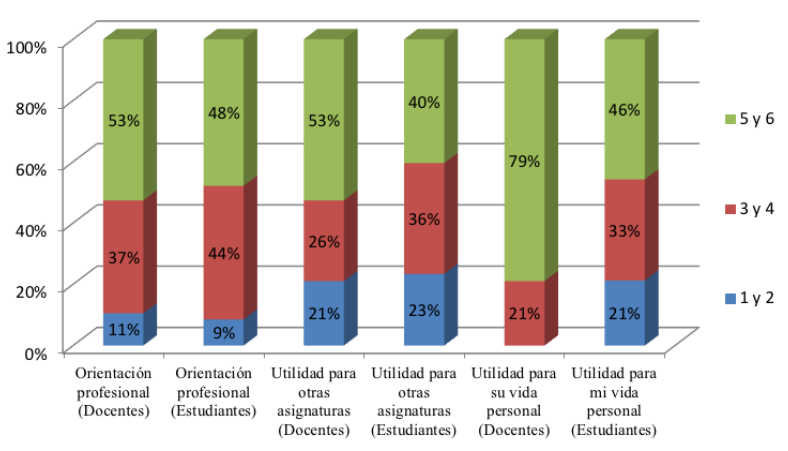

Estos resultados son coherentes con las siguientes declaraciones que hacen los alumnos de $4^{\circ}$ ESO y $2^{\circ}$ Bachillerato participantes en distintos proyectos de aprendizaje servicio, en las que podemos comprobar la influencia que perciben que tienen los aprendizajes adquiridos sobre otros contextos personales, tanto presentes como futuros.

He aprendido a perder la vergüenza cuando es necesario y a ayudar a las personas.

Me ha hecho pensar en cómo puede ser mi vejez.

[He aprendido a] Valorar más lo que tengo, ya que ellos con poco se divertían.

Lo que he aprendido me va a servir para las entrevistas de trabajo. Antes era muy tímido, muy vergonzoso, ahora soy más abierto.

Yo estoy en una asociación con personas discapacitadas y si el

Martín, E.; Solari,M.; De Vicente, J.; Luque, M.J.; Nieto, M.; Coll, C. (2018). La potencialidad del aprendizaje servicio para la personalización del aprendizaje escolar. RIDAS, Revista Iberoamericana de Aprendizaje Servicio, 5, 37-61. DOI10.1344/RIDAS2018.5.4 
instituto no me hubiera abierto estas puertas, no creo que estuviera ahí [...] Este año me voy a ir de voluntariado en el verano. Quizás incluso me dedique profesionalmente a esto $y$ eso me lo ha dado el instituto

4.4. Vinculación de los aprendizajes con las necesidades sociales del entorno

Una de las finalidades de los proyectos de aprendizaje servicio es que los aprendizajes se vinculen con las necesidades reales del entorno comunitario. Asimismo, hemos señalado que la realización de proyectos auténticos y complejos, así como la realización de aprendizajes socialmente relevantes, son dos estrategias adecuadas para la personalización de los aprendizajes escolares.

Esta meta se ha conseguido en gran medida aunque los estudiantes han hecho una valoración menos positiva que sus profesores. Como se puede ver en la siguiente gráfica, resulta alentador que la puntuación más alta en los alumnos sea el compromiso con la sociedad, que resulta un indicador de competencia más potente que el conocimiento de las necesidades o las entidades del entorno.
Gráfica 9: Valoración de docentes $(n=13)$ y estudiantes $(n=65)$ sobre la vinculación de los aprendizajes con el entorno comunitario ( $1=$ mínimo grado de acuerdo; 6= máximo grado de acuerdo)

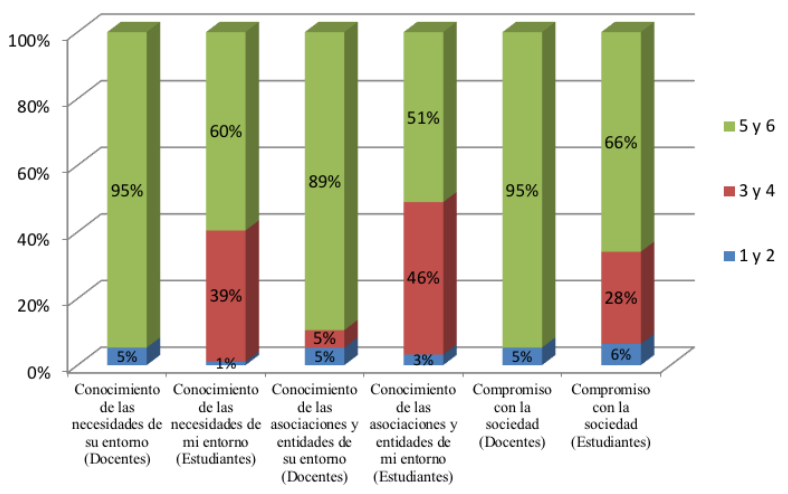

En la entrevista realizada a la técnico del Ayuntamiento, que forma parte del equipo coordinador del programa de aprendizaje servicio, ella destacaba que esta experiencia ha supuesto un cambio significativo en la participación social del municipio en general. Ello se debe, por una parte, a que otros institutos han incorporado la metodología de aprendizaje servicio en sus clases, a raíz de la experiencia del IES Miguel Catalán que ella ha difundido. Por otra parte, algunos de los proyectos han supuesto la participación directa de vecinos de Coslada, como el caso de las Jornadas Solidarias, que se organizan todos los años sobre distintos temas, el Maratón de donación de sangre, o la experiencia de Coslada City en los que los estudiantes entrevistaron a los vecinos, analizaron las políticas de la localidad y propusieron mejoras.

Asimismo, los antiguos alumnos del centro que siguen viviendo en Coslada mantienen, en muchos casos, actividades cívicas de esta naturaleza.

Martín, E.; Solari,M.; De Vicente, J.; Luque, M.J.; Nieto, M.; Coll, C. (2018). La potencialidad del aprendizaje servicio para la personalización del aprendizaje escolar. RIDAS, Revista Iberoamericana de Aprendizaje Servicio, 5, 37-61. DOI10.1344/RIDAS2018.5.4 
Ello se pone de manifiesto en el siguiente fragmento de una entrevista que realizamos a una de las estudiantes de $2^{\circ}$ de Bachillerato, que llevaba seis años participando en proyectos de aprendizaje servicio:

Claro que aunque hayamos dejado el instituto nos sigue influyendo. Muchos se han hecho donantes de sangre en cuanto han cumplido la edad, muchos siguen viniendo a las Jornadas Solidarias que se montan todos los años i¿De qué iban a venir a esto si no?!

4.5. Atención a los intereses y objetivos de aprendizaje del alumnado y aceptación de su capacidad para tomar decisions

Uno de los criterios de valor más importante de una metodología es su capacidad de permitir atender a la diversidad del alumnado ajustando la enseñanza a sus conocimientos previos y a su peculiar ritmo y estilo de aprendizaje. Cuando se ha preguntado a los docentes el grado de acuerdo con la afirmación Los proyectos de aprendizaje servicio me ayudan a atender a la diversidad del alumnado, el $84 \%$ de ellos se ha mostrado de acuerdo o muy de acuerdo.

Por otra parte, como hemos desarrollado en el marco teórico, tan importante como atender a la diversidad de los estudiantes en la dimensión intelectual o cognitiva del aprendizaje es hacerlo desde sus intereses y facilitar su participación en los distintos pasos del proceso, como medio para promover la realización de aprendizajes a los que puedan atribuir un sentido personal.

Si bien en los proyectos aprendizaje servicio se procura que el alumnado participe lo máximo posible y tome decisiones a lo largo de todo el proyecto, en la siguiente gráfica se puede observar que es en la fase de ejecución en la que los estudiantes más perciben su capacidad de tomar decisiones, siendo menor el nivel de participación que consideran que tienen en las fases de planificación y evaluación del proyecto.

\section{Gráfica 10: Valoración de los estudiantes} $(n=65)$ sobre su participación y capacidad de tomar decisiones en las distintas fases del proyecto ( $1=$ mínimo grado de acuerdo; $6=$ máximo grado de acuerdo)

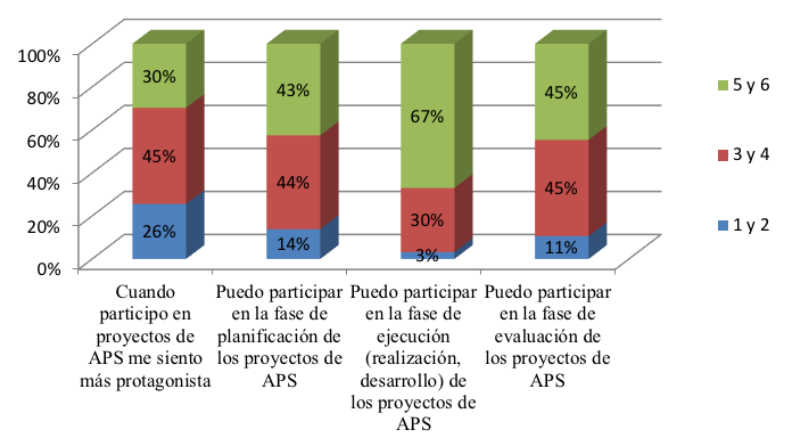

Los anteriores resultados son coherentes con la perspectiva del profesorado, que mayoritariamente considera que debería promover en mayor medida la autogestión y participación de sus estudiantes en los proyectos de aprendizaje servicio.

Martín, E.; Solari,M.; De Vicente, J.; Luque, M.J.; Nieto, M.; Coll, C. (2018). La potencialidad del aprendizaje servicio para la personalización del aprendizaje escolar. RIDAS, Revista Iberoamericana de Aprendizaje Servicio, 5, 37-61. DOI10.1344/RIDAS2018.5.4 
Gráfica 11: Grado de acuerdo del profesorado $(n=13)$ con la afirmación "Debería promover en mayor medida la autogestión y participación de mi alumnado en los proyectos de APS" (1= mínimo grado de acuerdo; 6= máximo grado de acuerdo)

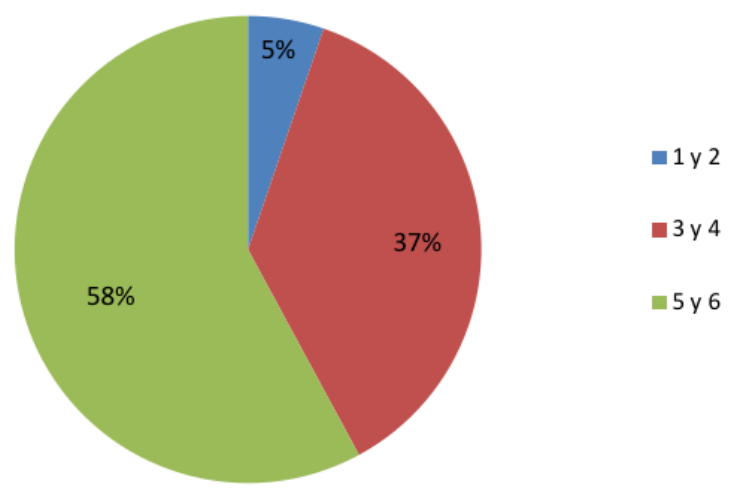

4.6. Reflexión de los estudiantes sobre sí mismos como aprendices

Como hemos desarrollado en el marco teórico, una de las estrategias orientadas a la personalización de los aprendizajes escolares consiste en favorecer la reflexión de los estudiantes sobre la visión que tienen de sí mismos como aprendices y sobre su manera de abordar las situaciones y actividades de aprendizaje.

El programa de aprendizaje servicio analizado cuenta entre sus virtudes con la potencialidad de haber permitido que los estudiantes descubrieran capacidades de sí mismos que en otras actividades escolares quedaban ocultas. En las entrevistas realizadas, los alumnos aludían a ello con mucha frecuencia:

Lo bueno es que se valorizan las cosas que tenemos, $y$ eso nos quita la vergüenza. Yo he visto que soy más abierto de lo que creia.

\section{Haber podido hablar con un desconocido con confianza fue raro, no sabíamos si íbamos a saber hacerlo.}

Cuando te ves en la situación, te pones, pero si no hicieras esta actividad no sabrías que eres capaz.

En coherencia con los anteriores fragmentos de entrevistas, en el cuestionario la mayor parte del alumnado también manifestó que durante la realización de los proyectos de aprendizaje servicio reflexionan sobre lo que están aprendiendo. Como se puede observar en la siguiente gráfica, esta afirmación contrasta con la perspectiva del profesorado, que considera que no siempre promueven esta reflexión a lo largo del proyecto.

Gráfica 12: Valoración de docentes $(n=13)$ y estudiantes $(n=65)$ acerca de la reflexión sobre sus procesos de aprendizaje que tiene lugar durante el proyecto ( $1=$ mínimo grado de acuerdo; $6=$ máximo grado de acuerdo

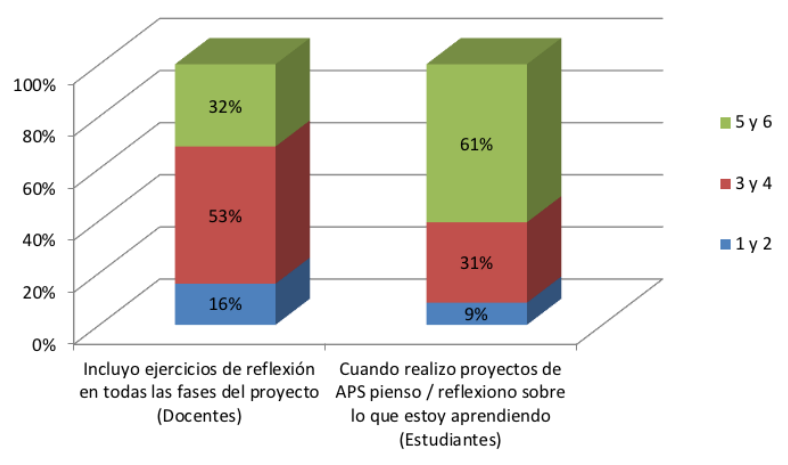

En este sentido, los docentes señalan en las entrevistas que se podría avanzar en la toma de conciencia de estas fortalezas del alumnado haciéndoles reflexionar de una forma más sistemática sobre la experiencia de

Martín, E.; Solari,M.; De Vicente, J.; Luque, M.J.; Nieto, M.; Coll, C. (2018). La potencialidad del aprendizaje servicio para la personalización del aprendizaje escolar. RIDAS, Revista Iberoamericana de Aprendizaje Servicio, 5, 37-61. DOI10.1344/RIDAS2018.5.4 
aprendizaje que están teniendo. Ello repercutiría en un mejor conocimiento de sus características como aprendices y también en su concepción de lo que creen que es aprender, tal y como señala un docente de Memoria Histórica.

Ellos se ven más valiosos. No es que esto sea uno de los aspectos buenos del ApS, es que es la clave. Pero nos falta ponerles nombre a las sensaciones que tienen. Yo he observado que verbalizando se aprende mucho más. Yo se lo digo siempre, es la máxima responsabilidad que tenemos, dar moral.

Por otra parte, también se reconoce en las entrevistas, tanto por parte de los estudiantes como de los docentes, que sería bueno que estas capacidades más desconocidas de sí mismos se pudieran hacer llegar al resto de los profesores que les dan clase y a las familias. El reconocimiento de estas personas contribuiría a reforzar la imagen que los propios aprendices tienen sobre sí mismos e influiría, a su vez, en las expectativas de los adultos. Existe un acuerdo sobre el interés de estas posibles iniciativas, aunque se es consciente de la dificultad que entrañan, como se pone de manifiesto a continuación por parte de estudiantes de $4^{\circ}$ ESO:

Me hubiera gustado que me vieran algunos profes porque yo en clase hablo poco. En clase si dices algo mal, te bajan la nota, pero aquí si te equivocas no pasa nada. Lo hemos dicho, se corrige y se pasa [...] Y me hubiera gustado que me hubieran visto, porque no es lo mismo que contarlo.

Sí, lo vamos a contar en casa, porque estoy orgulloso.

Los profesores del proyecto de Memoria Histórica señalan:

No es fácil transmitírselo a los otros profesores porque no están en el ApS y no les puedes obligar a hacer nada.

Con las familias, podríamos comentarlo en la reunión, aunque también es posible que a los alumnos les de pudor contárselo a sus padres.

Y la coordinadora del proyecto de aprendizaje servicio manifiesta:

El otro día nos llamó una madre porque no se creía que su hijo estuviera haciendo lo que le había dicho. Le parecía imposible que estuviera dedicando tiempo a una actividad como esta.

Fuertemente relacionado con lo anterior, la construcción de aprendizajes con sentido tiene la potencialidad de contribuir a la (re)construcción de la identidad de los alumnos, aspecto que se ha puesto de manifiesto en la valoración que el profesorado y alumnado hace sobre el grado en que la participación en los proyectos de aprendizaje servicio ha contribuido a mejorar el autoestima de los estudiantes, como se refleja en la siguiente gráfica.

Martín, E.; Solari,M.; De Vicente, J.; Luque, M.J.; Nieto, M.; Coll, C. (2018). La potencialidad del aprendizaje servicio para la personalización del aprendizaje escolar. RIDAS, Revista Iberoamericana de Aprendizaje Servicio, 5, 37-61. DOI10.1344/RIDAS2018.5.4 
Gráfica 12: Grado de acuerdo de docentes $(n=13)$ y estudiantes $(n=65)$ con la afirmación relativa a que la participación en el proyecto contribuye al aumento del autoestima del alumnado ( $1=$ mínimo grado de acuerdo; $6=$ máximo grado de acuerdo)

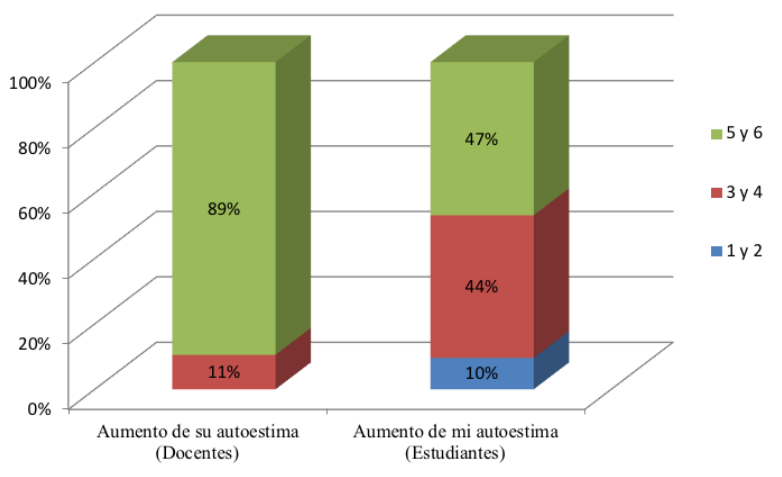

\section{Conclusiones}

A partir de los resultados que hemos obtenido del análisis del primer ciclo de la investigación llevada a cabo en el IES Miguel Catalán, podemos sacar algunas conclusiones que agruparemos en torno a tres grandes ejes: 1) la contribución de la experiencia de aprendizaje servicio analizada para la realización de aprendizajes con un sentido y un valor personal para los estudiantes, 2) los ámbitos que, a la luz de los datos obtenidos, pueden mejorarse para seguir avanzando hacia una mayor personalización de los aprendizajes escolares, en el contexto de este programa de ApS, y 3) algunas conclusiones sobre la metodología de investigación utilizada.

Aunque en el apartado de resultados lo hemos desarrollado con mayor detenimiento, queremos destacar la pertinencia de analizar las experiencias de aprendizaje servicio desde el marco teórico de la personalización. Consideramos que los resultados presentados en este artículo legitiman la relevancia de añadir esta perspectiva teórica a los variados enfoques mediante los que se suelen realizar investigaciones sobre la metodología de aprendizaje servicio. La principal contribución que, desde nuestro punto de vista, tiene el marco de la personalización es que sitúa el foco de análisis en los procesos de atribución de sentido que necesariamente deberían tener lugar en este tipo de proyectos.

El análisis de la información recogida nos ha permitido identificar ciertos ámbitos de mejora que, de acuerdo con la metodología de la investigación, han sido discutidos con los docentes implicados, con la finalidad de elaborar un plan de mejora que se ha puesto en marcha en el segundo ciclo de la investigación. En concreto, los ámbitos de mejora identificados implican:

- Favorecer una mayor participación y toma de decisiones de los estudiantes en las tareas de todas las fases de los proyectos

- Poner en marcha iniciativas para aumentar los procesos de toma de conciencia de los estudiantes acerca de los cambios en su identidad de aprendiz

- Mejorar la difusión del programa a las familias, con el fin de incidir en la imagen que tienen de sus hijos como aprendices y fortalecer la vinculación de la escuela con el entorno comunitario

- Mejorar los procesos de evaluación de los aprendizajes, para poder

Martín, E.; Solari,M.; De Vicente, J.; Luque, M.J.; Nieto, M.; Coll, C. (2018). La potencialidad del aprendizaje servicio para la personalización del aprendizaje escolar. RIDAS, Revista Iberoamericana de Aprendizaje Servicio, 5, 37-61. DOI10.1344/RIDAS2018.5.4 
valorar más adecuadamente la medida en que los alumnos han desarrollado ciertas competencias

Por último, en lo que se refiere al propio diseño metodológico de la investigación, podemos sacar, al menos, cuatro conclusiones. En primer lugar, hemos propuesto un diseño y unas dimensiones de análisis que se derivan claramente de la conceptualización que hemos hecho de personalización de los aprendizajes escolares, lo que contribuye a su congruencia metodológica (Creswell, 2013).

En segundo lugar, la realización de un estudio de caso longitudinal nos ha permitido investigar en profundidad el proceso de implementación y transformación de un programa concreto de aprendizaje servicio (estudio de caso), atendiendo a su naturaleza cambiante a lo largo del tiempo (estudio longitudinal) y del espacio (recogida de información en distintos proyectos y contextos de actividad en los que participaban los estudiantes, dentro y fuera del centro).

En tercer lugar, las estrategias de recogida de información que hemos utilizado han contribuido no solamente a recoger las voces de los distintos agentes de la comunidad educativa, sino que también nos han permitido triangular información procedente de fuentes de información complementarias (observaciones, entrevistas, cuestionarios, documentos), aumentando de este modo la calidad de la investigación.

En cuarto lugar, hemos comprobado la adecuación del enfoque de investigación basada en el diseño y la implementación de propuestas educativas -Design-based implementation research- (Fishman et al., 2013) debido a que, a diferencia de otras metodologías que acrecientan la distancia entre los participantes y los investigadores, hemos podido establecer una relación de colaboración y análisis conjunto con el profesorado. Ello ha contribuido no solamente a que podamos tener en cuenta su voz en los análisis (aspecto que contribuye a mejorar la calidad y rigor de la investigación), sino que también les ha otorgado un papel protagónico en la reflexión sobre su propia práctica docente y en el re-diseño de estrategias para orientarla hacia una mayor personalización de los aprendizajes escolares de sus alumnos.

Una de las limitaciones de este trabajo se deriva justamente del diseño metodológico (estudio de caso longitudinal), ya que las conclusiones a las que hemos llegado cobran sentido dentro de la experiencia de aprendizaje servicio estudiada $y$, en consecuencia, los resultados no son directamente extrapolables a otros casos. No obstante, al tratarse de un caso dentro de una investigación de mayor envergadura que analiza la potencialidad de otras experiencias de innovación para la construcción de aprendizajes con sentido, los resultados obtenidos estudiando este programa de ApS pueden constituir un material relevante que, a la luz de los resultados obtenidos en los restantes casos, nos permitan seguir avanzando hacia la identificación de algunos facilitadores y

Martín, E.; Solari,M.; De Vicente, J.; Luque, M.J.; Nieto, M.; Coll, C. (2018). La potencialidad del aprendizaje servicio para la personalización del aprendizaje escolar. RIDAS, Revista Iberoamericana de Aprendizaje Servicio, 5, 37-61. DOI10.1344/RIDAS2018.5.4 
obstáculos presentes en las prácticas dirigidas a la personalización de los aprendizajes escolares.

\section{Referencias bibliográficas}

Barron, B. (2010). Conceptualizing and Tracing Learning Pathways over Time and Setting. National Society for the Study of Education, 109 (1), 113-127.

Batlle, R. (2011). ¿De qué hablamos cuando hablamos de AprendizajeServicio? Revista Crítica, 972, 49-54.

Batlle, R. (2013). El AprendizajeServicio en España: el contagio de una revolución pedagógica necesaria. Barcelona: PPC.

Caïs, J., Folguera, L., y Formoso, C. (2014). Investigación cualitativa longitudinal. Madrid: Centro de Investigaciones Sociológicas.

Coll (2009) Enseñar y aprender en el siglo XXI: el sentido de los aprendizajes escolares. En A. Marchesi, J. C. Tedesco y C. Coll (Coords.), Reformas educativas y calidad de la educación (pp. 101-112). Madrid: OEI / Fundación Santillana. Disponible en http://www.psyed.edu.es/prodGrintie/c ap libros/CC EnsenarAprenderSigloXXI . pdf

Coll, C. (2013a). El currículo escolar en el marco de la nueva ecología del aprendizaje. Aula de Innovación Educativa, 219, 31-36.

Coll, C. (2013b). La educación formal en la nueva ecología del aprendizaje: tendencias, retos y agenda de investigación. En J. L. Rodríguez Illera (Comp.), Aprendizaje y Educación en la
Sociedad Digital (pp. 156-170).

Barcelona: Universitat de Barcelona.

Coll, C. (2016). La personalització de I'aprenentatge escolar. El què, el per què i el com d'un repte indefugible. En J. M. Vilalta (Dr.) Reptes de l'educació a Catalunya. Anuari d'Educació 2015. Barcelona: Fundació Jaume Bofill.

Coll, C. (en prensa). La personalización del aprendizaje escolar, una exigencia de la nueva ecología del aprendizaje. En Dosier Graó De la atención a la diversidad a la personalización del aprendizaje: continuidad y salto cualitativo. Barcelona: Graó.

Creswell, J. W. (2013). Qualitative inquiry \& research design. Choosing among five Approaches. Thousand Oaks: SAGE.

Del Olmo, M. (2008). El trabajo de campo etnográfico: una introducción para los que no lo han hecho nunca. En J. A. Téllez (Ed.), Educación intercultural: miradas multidisciplinares (pp. 83-95). Madrid: Catarata.

Engel, A. y Membrive, A. (en prensa). Contextos de actividad, experiencias de aprendizaje y trayectorias personales: la articulación de los aprendizajes escolares y no escolares. En Dosier Graó De la atención a la diversidad a la personalización del aprendizaje: continuidad y salto cualitativo. Barcelona: Graó.

Fishman, B., Penuel, W., Allen, A., Cheng, B., Sabelli, N. (2013). Designbased implementation research: an emerging model for transforming the relationship of research and practice. National Society for the Study of

Martín, E.; Solari,M.; De Vicente, J.; Luque, M.J.; Nieto, M.; Coll, C. (2018). La potencialidad del aprendizaje servicio para la personalización del aprendizaje escolar. RIDAS, Revista Iberoamericana de Aprendizaje Servicio, 5, 37-61. DOI10.1344/RIDAS2018.5.4 
Education, 112 (2), 136-156.

Furco, A. y Billig, S. (2001). Servicelearning: The essence of the Pedagogy. New York: Information Age Publishing.

Furco, A. y Root, S. (2010). Research Demonstrates the Value of Service Learning. Phi Delta Kappan, 91 (5), 1620.

Kumpulainen, K., y Sefton-Green, J. (2014). What is Connected Learning and how to research it? International Journal of Learning and Media, 4 (2), 7-18.

Martín, E., y Moreno, A. (2007). La competencia de aprender a aprender. Madrid. Alianza Editorial.

Martín, X. (2009). La pedagogía del aprendizaje servicio. En J. M. Puig Rovira (coord.). Aprendizaje Servicio (ApS) Educación y compromiso cívico (pp. 107-126). Barcelona: Graó.

Martín, X. (2016). Proyectos con alma. Trabajo por proyectos con servicio a la comunidad. Barcelona: Graó.

Puig Rovira, J. M., Batlle, R., Bosch, C., Palos, J. (2006). Aprenentatge Servei. Educar per a la ciutadania. Barcelona: Octaedro y Fundació Jaume Bofill

Puig Rovira, J. M., Gijón, M., Martín, X., Rubio, L. (2011). Aprendizaje-servicio y Educación para la ciudadanía. Revista de Educación, número extraordinario 2011, 45-67

Rubio, L. (2009). El aprendizaje en el aprendizaje servicio. En J. M. Puig Rovira (coord.). Aprendizaje Servicio (ApS) Educación y compromiso cívico (pp. 91-105). Barcelona: Graó.

Stake, R. (1998). Investigación con estudio de casos. Madrid: Morata.

Tapia (2001). La solidaridad como pedagogía. El "aprendizaje-servicio" en la escuela. Buenos Aires: Editorial ciudad Nueva.

\section{AGRADECIMIENTOS}

Este trabajo se ha realizado en el marco del proyecto de investigación Aprender con sentido. Estrategias, instrumentos y prácticas de personalización del aprendizaje escolar (FBiG 308977) dirigido por César Coll (Universidad de Barcelona) y financiado por el Instituto de Tecnologías, Educación y Aprendizaje de la Fundación SM.

Martín, E.; Solari,M.; De Vicente, J.; Luque, M.J.; Nieto, M.; Coll, C. (2018). La potencialidad del aprendizaje servicio para la personalización del aprendizaje escolar. RIDAS, Revista Iberoamericana de Aprendizaje Servicio, 5, 37-61. DOI10.1344/RIDAS2018.5.4 